\title{
Influence of prevailing weather parameters on population dynamics of spotted stem borer, Chilo partellus (Swinhoe) and its natural enemies on maize in Haryana
}

\author{
GAURAV SINGH ${ }^{1,2 *}$, MAHA SINGH JAGLAN ${ }^{3}$, TARUN VERMA ${ }^{2}$, and SHIVANI KHOKHAR ${ }^{4}$ \\ ${ }^{1}$ Hawkesbury Institute for The Environment, Western Sydney University, Penrith, New South Wales, Australia, 2751, \\ ${ }^{2}$ Department of Entomology, CCS Haryana Agricultural University, Hisar, India, 125004, ${ }^{3}$ CCS Haryana Agricultural \\ University, Regional Research Station, Karnal, India, 132001, ${ }^{4}$ Department of Entomology, Punjab Agricultural University, \\ Ludhiana, India, 141004 \\ *Corresponding author email: Gaurav.ssingh0001@gmail.com
}

\begin{abstract}
The experiment was conducted at CCS Haryana Agricultural University Regional Research Station, Karnal to ascertain the influence of prevailing meteorological parameters on population dynamics of Chilo partellus and its natural enemies on maize during Kharif, 2017. Maximum oviposition (0.75 egg masses per plant) was recorded during $28^{\text {th }}$ standard meteorological week (SMW) whereas larval population was at peak during $31^{\text {st }}$ SMW (3.8 larvae per plant). Cumulative $(47.5 \%)$ and fresh plant infestation $(11.5 \%)$ were maximum during $34^{\text {th }}$ and $28^{\text {th }}$ SMW, respectively. Maximum egg parasitisation $(6.53 \%)$ by Trichogramma sp. and larval parasitisation $(31.64 \%)$ by Cotesia flavipes was recorded during $28^{\text {th }}$ and $33^{\text {rd }}$ SMW, respectively. Changes in pest population were correlated and regressed with weather parameters. Egg and larval populations of $C$. partellus and parasitisation by Trichogramma sp. exhibited significant positive correlation with average minimum temperature whereas $C$. flavipes exhibited significant negative correlation with average maximum temperature $(r=-0.741)$ and highly significant positive correlation with evening relative humidity $(r=0.695)$. Plant infestation and dead heart formation were significantly correlated with average minimum temperature and non-significantly correlated with all other weather parameters. The multiple linear regression analysis explained the variability due to various weather parameters. This information can be utilised while formulating integrated management tactics against this pest.
\end{abstract}

Key words: Seasonal incidence, Trichogramma, Cotesia flavipes, parasitisation, biological control

Maize (Zea mays L.) is popularly known as "Queen of cereals" due to its extraordinary level of genotypic diversity and highest genetic yield potential. Its wider genetic base and adaptability enables it to thrive under different agroclimatic zones of India (Singh and Jaglan, 2018) and grown over an area of 9.63 million ha producing 25.90 million MT of maize annually (Indiastat, 2018). Although the area under maize cultivation has increased considerably, the productivity is still lower than global average due to various biotic and abiotic constraints and among them insect-pests are considered as major yield reducing factors (Ngoko et al., 2002). Around 250 species of insect and mite pests have been reported attacking maize at different stages of crop growth (Mathur, 1991). Among them, spotted stem borer, Chilo partellus (Swinhoe) (Lepidoptera: Crambidae) is the most serious insect-pest of maize in India as well as other Asian countries (Singh et al., 2018). Pest infestation starts from 10-15 days after germination when neonate larvae scrap off the chlorophyll content of newly emerged leaves and finds their way into the leaf sheath where they feast upon the growing stem of tender plants (Singh et al., 2018). Pin hole formation, dead hearts and stem tunneling are the characteristic damaging symptoms of the pest infestation and it reportedly cause up to 80.4 per cent yield reduction in different agro-climatic zones of the country (Panwar et al., 2000; Reddy and Zehr, 2004). It has become a serious threat in maize and sorghum based cropping systems not only in India and Asia but also throughout the world (Sylvain et al., 2015 ). It has attained the status of key pest causing 18 to $25 \%$ yield losses in maize and has also been reported feeding on paddy, sugarcane and other millets (Harris, 1990; Kumar and Kanta, 2011). Due to internal nature of damage, this pest is very difficult to control by conventional insecticides. Thus, it is necessary to have basic knowledge about pest biology and ecology to effectively manage it under different sets of agro-climatic conditions.

Studies on seasonal incidence of insect-pests in 
relation to abiotic and biotic factors are imperative for better understanding of pest scenario in different agro-climatic and agro-ecological zones. It helps in determining weak link in insect-pest life cycle and ultimately, in developing effective pest management strategies (Fand et al., 2018). Scrutiny of literature revealed that information on influence of weather parameters on population dynamics of $C$. partellus and its natural enemies on maize is scanty under this part of the country. Keeping this in view, population dynamics of $C$. partellus and its relation with prevailing weather parameters in Haryana conditions were studied.

\section{MATERIALAND METHODS}

The experiment was conducted at research area of CCS Haryana Agricultural University, Regional Research Station, Karnal (Haryana) during Kharif, 2017. Maize crop was sown during last week of June ( $\left.26^{\text {th }} \mathrm{SMW}\right)$ by following all the recommended package of practices (CCS Haryana Agricultural University) except pesticide application. Maize genotype, HM 10 was raised on a plot size of $125 \mathrm{~m}^{2}$ by adopting $75 \mathrm{~cm} X 20 \mathrm{~cm}$ spacing in randomized block design and replicated four times. All life stages of C. partellus were observed at weekly interval starting from five days after germination (DAG) till harvesting of the crop.

A total of 25 plants were randomly tagged in each replication at weekly interval and observations were recorded on egg masses, larval population, pupal counts, and natural enemies. Tagged plants were uprooted on the very next day, brought to the laboratory and dissected on the same day by longitudinally splitting the stem for recording larval and pupal population. Larvae obtained from the split stems were reared in the laboratory till pupation on cut pieces of maize stem to record the presence of larval parasitoids, Cotesia flavipes (Cameron). The average number of $C$. flavipes larvae emerged from the collected C. partellus larvae, parasitisation rate and average number of $C$. flavipes cocoons per parasitized larva were quantified at weekly interval. $C$. partellus egg masses from the tagged plants were transferred to Petri-plates and kept at room temperature for incubation. Thereafter, individual eggs were observed under stereo zoom microscope for the presence of egg parasitoids, if any. Pupae were kept in the glass jars filled with moist sand to allow adult emergence and record the presence of pupal parasitisation.

For recording plant infestation and dead heart formation, 100 plants per replicate were selected randomly and tagged 5 DAG (days after germination) of crop. Total number of damaged plants and dead hearts were counted starting from 5 DAG till harvesting of the crop and expressed as per cent infestation and dead hearts. Total plant infestation and dead heart formation up to each standard meteorological week (SMW) were expressed as cumulative plant infestation (\%) and cumulative dead hearts (\%), respectively whereas weekly fresh infested plants and dead hearts were expressed as fresh plant infestation (\%) and fresh dead hearts (\%), respectively.

The weather data of different standard meteorological weeks (SMW) during crop growth period was obtained from the meteorological observatory of Central Soil Salinity Research Institute (CSSRI), Karnal. Correlation co-efficient and multiple linear regression of different abiotic factors (temperature, relative humidity, rainfall, sunshine hours) with seasonal incidence of $C$. partellus and its natural enemies was estimated using OPSTAT software (http:// 192.168.2.174/opstat/default.asp) i.e. online platform for on-campus user.

\section{RESULTS AND DISCUSSION}

\section{Egg masses of C. partellus in relation to weather parameters}

Oviposition started during $27^{\text {th }}$ SMW (first week of July, 5 DAG) and most of the egg masses were recorded on leaf blades, lower leaves and under surface of leaves (Neupane et al., 1985). Initially, the mean egg masses were low (0.30 egg masses/plant) during the $27^{\text {th }}$ SMW which attained the peak ( 0.75 egg masses/plant) during $28^{\text {th }}$ SMW (Table 1). Thereafter, a declining trend was observed in the egg laying up to $31^{\text {st }}$ SMW and no further egg laying was recorded. In contrast, Divya et al. (2009) recorded maximum egg laying (0.09 egg masses per plant) on sweet sorghum during $37^{\text {th }}$ SMW in Dharwad. This could be due to difference in crops and agro-climatic conditions of these regions.

C. partellus egg masses exhibited highly significant positive correlation with average minimum temperature $(\mathrm{r}=0.775)$ and significant negative correlation with morning relative humidity $(\mathrm{r}=-0.593)$ whereas it was non- significantly correlated with other weather variables (Table 2).

\section{Egg parasitisation of $C$. partellus in relation to weather parameters}

Eggs of C. partellus were majorly parasitized by egg parasitoid, Trichogramma sp. from $27^{\text {th }}$ SMW ( $1^{\text {st }}$ week of July, 5 DAG) to $31^{\text {st }}$ SMW (last week of July, 33 DAG) and the extent of parasitisation ranged from 0.80 to 6.53 per cent (Table 1). Similarly, T. chilonis was first recorded during mid- 
1 (a)

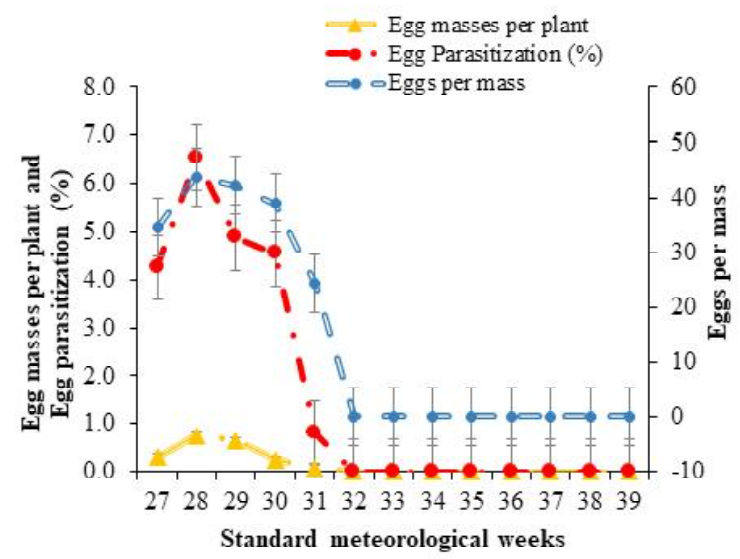

1 (b)

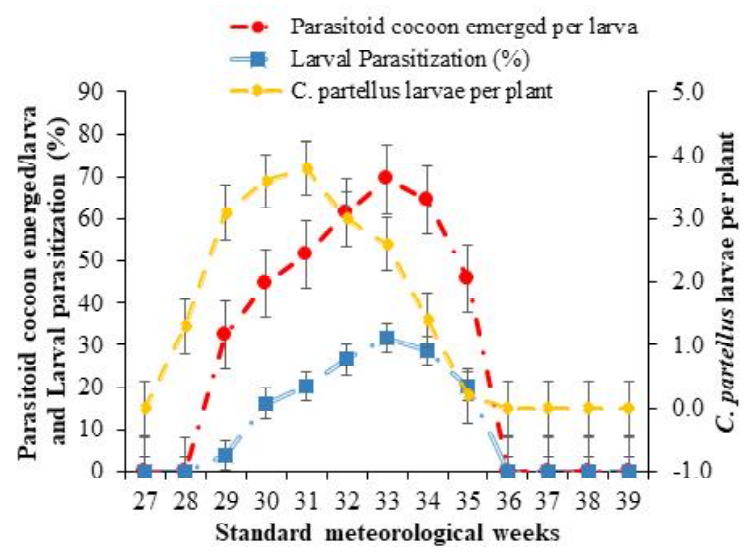

Fig.1: Parasitisation of C. partellus by egg parasitoid, Trichogramma sp. (1a) and larval parasitoid.

July and extent of parasitisation varied from 14 to 40 per cent in Pakistan (Farid et al., 2007). Contrary to Jalali \& Singh, 2003, we observed low rate of parasitisation during early stages when egg masses per plant ( 0.30 egg masses/ plant) and eggs per mass (34.56 eggs/mass) were low. However, parasitisation increased considerably with increase in egg masses per plant ( 0.75 egg masses/plant) and eggs per mass (43.78 eggs/mass) during $28^{\text {th }}$ SMW (Fig 1a), and no egg parasitisation was recorded after $31^{\text {st }} \mathrm{SMW}$ due to cessation of egg laying by C. partellus (Fig 1a).

Egg parasitoid, Trichogramma sp. exhibited highly significant positive correlation with average minimum temperature $(\mathrm{r}=0.797)$ and negative correlation with morning relative humidity $(\mathrm{r}=-0.506)$ (Table 2$)$. Likewise, $T$. chilonis had highly significant and positive correlation with temperature $(\mathrm{r}=0.718)$ but non-significant relation with relative humidity in Pakistan (Ahmad et al., 2017). Interestingly, it exhibited significant positive correlation with eggs masses $(\mathrm{r}=0.941)$ and eggs per mass $(\mathrm{r}=0.957)$ of C. partellus indicating a proportionate increase in parasitisation with increase in number of eggs laid (Table 3). Same was reported by Pats et al., (1997) suggesting a positive density dependent response.

\section{Larval population of $C$. partellus and weather parameters}

During early stages of crop, larval population was confined to fewer plants but as the crop grew older, population increased during $2^{\text {nd }}$ and $3^{\text {rd }}$ week after crop emergence (Dharmasena, 2002) and it spread all over the field. Larval population of C. partellus was first noticed during the $28^{\text {th }}$ SMW (second week of July) and increased up to $31^{\text {st }}$ SMW (last week of July). It experienced a declining trend which continued up to $35^{\text {th }}$ SMW (last week of August) (Table 1) and no larval population was observed thereafter. Mohan et al. (1990) also reported maximum larval population from $3^{\text {rd }}$ week of August to $2^{\text {nd }}$ week of September in Kharif sorghum in Haryana.

C. partellus remains active from March to November in Northern plains of India (Panwar, 2005) but mainly infest Kharif maize during $1^{\text {st }}$ week of July to $2^{\text {nd }}$ week of September with peak activity during August (Patel, 2005). Pest population was found to be active from $3^{\text {rd }}$ week of July to $3^{\text {rd }}$ week of September with maximum population (1.12 larvae/plant) during August (34 $4^{\text {th }}$ SMW) (Patel et al., 2016) and its incidence was higher during July-August sown crop as compared to September-October sown crop in South India (Trehan and Butani, 1949). However, Divya et al. (2009) reported maximum larval population in the month of October (0.4 larvae/plant) during Kharif season at Dharwad. These variations in the peak activity period could be due to different growing seasons and different meteorological factors prevailing at the time of experimentation.

Larval population of $C$. partellus exhibited significant positive correlation with minimum temperature and evening relative humidity (Table 2) which was also reported by Patel et al. (2016). Larval population was non-significantly correlated with rainfall, however, Patel (2005) reported significant positive correlation with rainfall. Kandalkar et al. (2000) also reported non-significant correlation with maximum temperature, morning relative humidity, evening relative humidity, total rainfall but contrary to our findings, larval population was found to be significantly negatively correlated $(\mathrm{r}=-0.734)$ with minimum temperature in their study. 
2 (a)

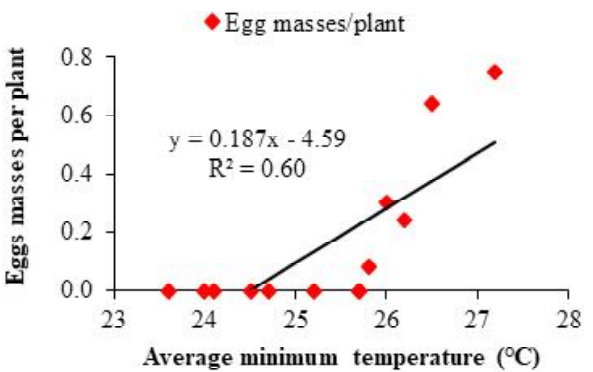

2 (c)

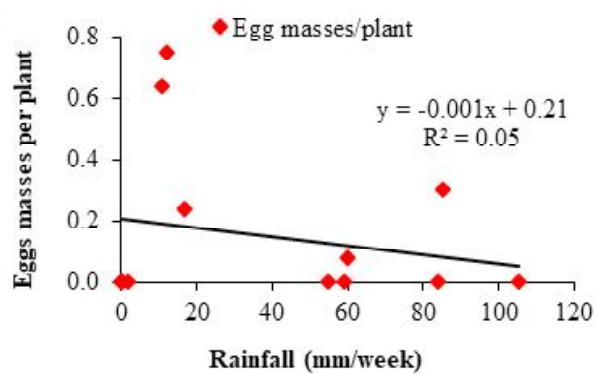

$2(\mathrm{e})$

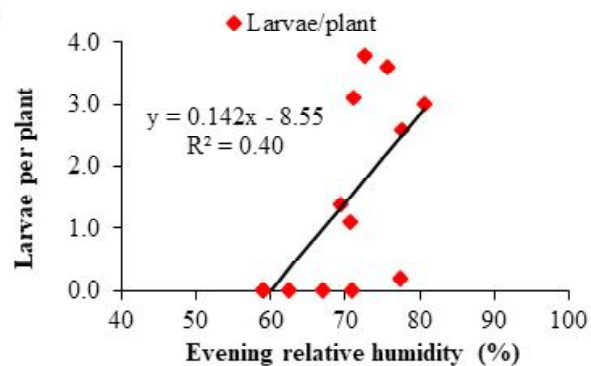

2 (b)

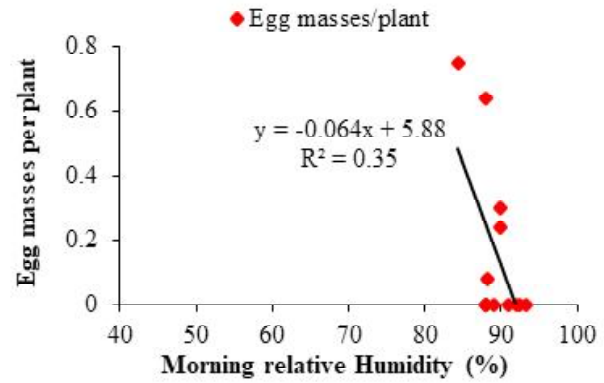

2 (d)

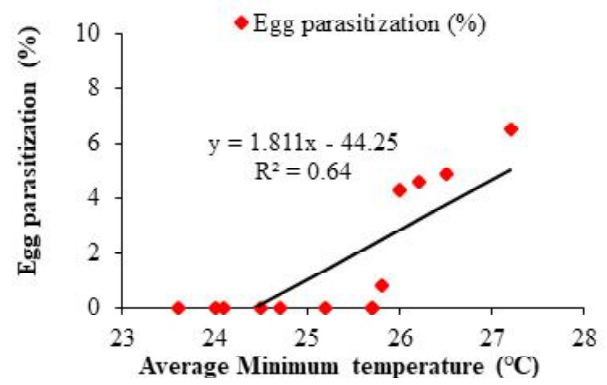

2 (f)

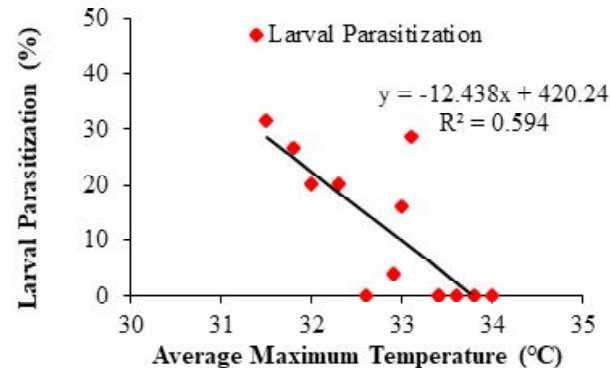

Fig.2: Linear regression line plots of C. partellus egg masses with average minimum temperature (2a), morning relative humidity (2b), rainfall (2c), egg parasitisation by egg parasitoid, Trichogramma sp. with average minimum temperature (2d), larval population of $C$. partellus with evening relative humidity (2e) and larval parasitisation by braconid wasp, Cotesia flavipes with average maximum temperature (2f).

\section{Larval parasitisation of $C$. partellus in relation to weather parameters}

C. partellus larvae were majorly parasitized by Braconid parasitoid, Cotesia flavipes starting from 5 DAG till the maturity of the crop with maximum parasitisation (31.64 \%) during $33^{\text {rd }}$ SMW (Table 1). Mohan et al. (1991) reported 2.0 - 33.2 per cent larval parasitisation of $C$. partellus by C. flavipes on sorghum. Likewise, $35-50$ per cent larval parasitisation rates has been reported in Himachal Pradesh (Devi and Raj, 1996). Average number of cocoons formed per larva were maximum (69.34 cocoons per larva) when larval parasitisation was at peak ( $33^{\text {rd }}$ SMW) (Fig 1b). C. flavipes adult preferred late instar larvae of C. partellus and duration of pupal stage (cocoon formation to adult emergence) ( $5.05 \pm 0.25$ to $6.25 \pm 0.19$ days $)$ was minimum in cocoons emerged from final instar C. partellus larvae. $C$. flavipes preferred $4^{\text {th }}$ instar larvae and failed to complete life cycle on $1^{\text {st }}, 2^{\text {nd }}$ and $3^{\text {rd }}$ instars of C. partellus (Khan et al., 2017). They further reported significant difference in pupal duration of $C$. flavipes from parasitized $3^{\text {rd }}, 4^{\text {th }}$ and $5^{\text {th }}$ instar larvae $(6.46 \pm 0.13,5.06 \pm 0.21$ and $5.12 \pm 0.31$ days, respectively).

Larval parasitoid, C. flavipes had a highly significant negative correlation with maximum temperature $(\mathrm{r}=-0.741)$, highly significant positive correlation with evening relative humidity $(\mathrm{r}=0.695)$ and significant positive correlation with rainfall ( $\mathrm{r}=0.622$ ) (Table 2). Minimum temperature, morning relative humidity and sunshine hours were non-significantly correlated with $C$. flavipes activity. In contradiction, Shrivastava (2015) reported non-significant negative correlation with temperature, rainfall and positive significant correlation with relative humidity. These variations could be due to crop sown during different seasons and climatic conditions prevailing at the time of experimentation. A 
3(a)

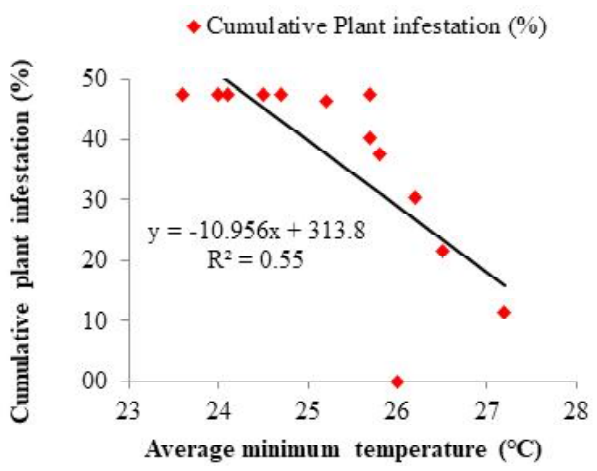

$3(\mathrm{c})$

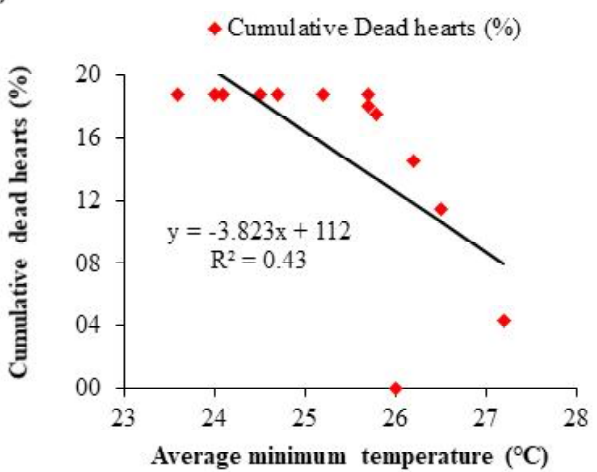

3 (b)

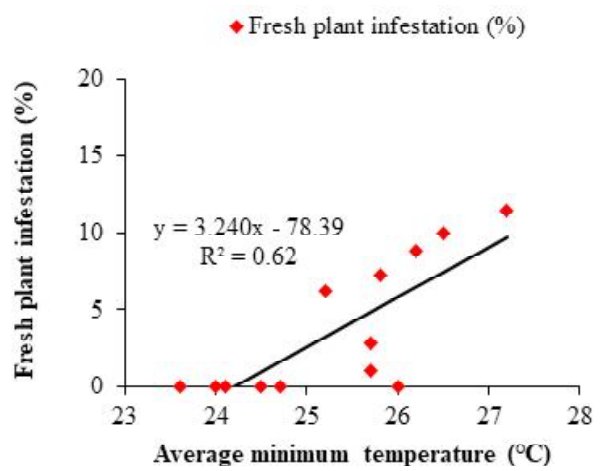

3 (d)

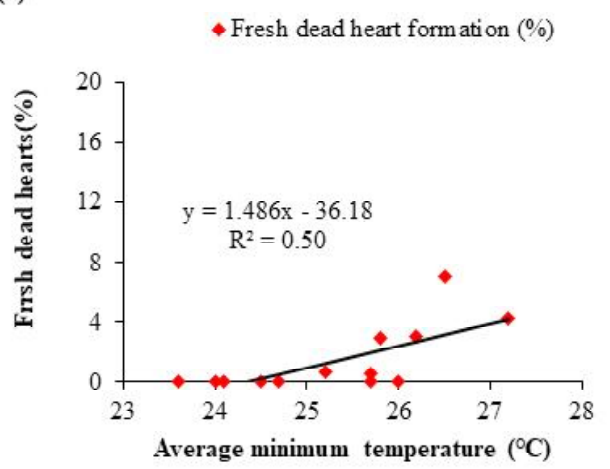

Fig.3: Linear regression line plots of C. partellus cumulative plant infestation (3a), fresh plant infestation (3b), cumulative dead heart formation (3c) and fresh dead heart formation (3d) with average minimum temperature.

significant positive correlation $(\mathrm{r}=0.591)$ was reported between larval population of $C$. partellus and parasitisation by C.flavipes (Table 3 ) which is in complete agreement with Patel et al. (2016).

\section{Pupal population of $C$. partellus and weather parameters}

Pupae of C. partellus were recovered from maize stem, under the leaf sheath, from mid-rib of leaves and even from maize cob. Larvae of $C$. partellus attained maturity and started transforming into pupae during $31^{\text {st }}$ SMW. The pupal population was maximum (1.5 pupae/plant) during $35^{\text {th }}$ SMW (last week of August) and declined thereafter (Table 1). Besides this, pupal population had a non-significant negative correlation with maximum temperature, minimum temperature and non-significant positive correlation with all other weather parameters (Table 2). Only one study regarding pupal density of $C$. partellus, where maximum number of pupae (19/50 plants) were recorded during $44^{\text {th }}$ SMW (Divya et al., 2009), was found in the literature.

In addition to egg and larval parasitoids, parasitisation by two pupal parasitoids, Tetrastichus sp. and Sturmiopsis sp. was also observed but their rate of parasitisation was very low (1.40-5.20\% and 0.80-2.40\%, respectively) (Rao et al., 2001).

\section{Plant infestation and dead heart formation by $C$. partellus}

Plant infestation by neonate larvae started during $28^{\text {th }}$ SMW (second week of July) and increased up to the maximum (47.5\%) during $34^{\text {th }}$ SMW (third week of August). No further plants were infested after this point due to the decrease in number of larvae and transformation of larval population into pupal stage (Table 1). However, maximum fresh plant infestation $(11.5 \%)$ was recorded during $28^{\text {th }}$ SMW which followed a declining trend afterwards up to $34^{\text {th }}$ SMW when only one per cent of fresh plants were infested.

Dead hearts were first observed during $28^{\text {th }}$ SMW $(4.3 \%)$ and increased gradually to the peak value (18.8 per cent) during $33^{\text {rd }}$ SMW (Table 1), and no further increase in dead hearts was observed. On the other hand, maximum fresh dead hearts $(7.1 \%)$ were recorded during $29^{\text {th }}$ SMW and declined afterwards up to $33^{\text {th }}$ SMW when only 0.7 per cent of fresh dead hearts were observed. 


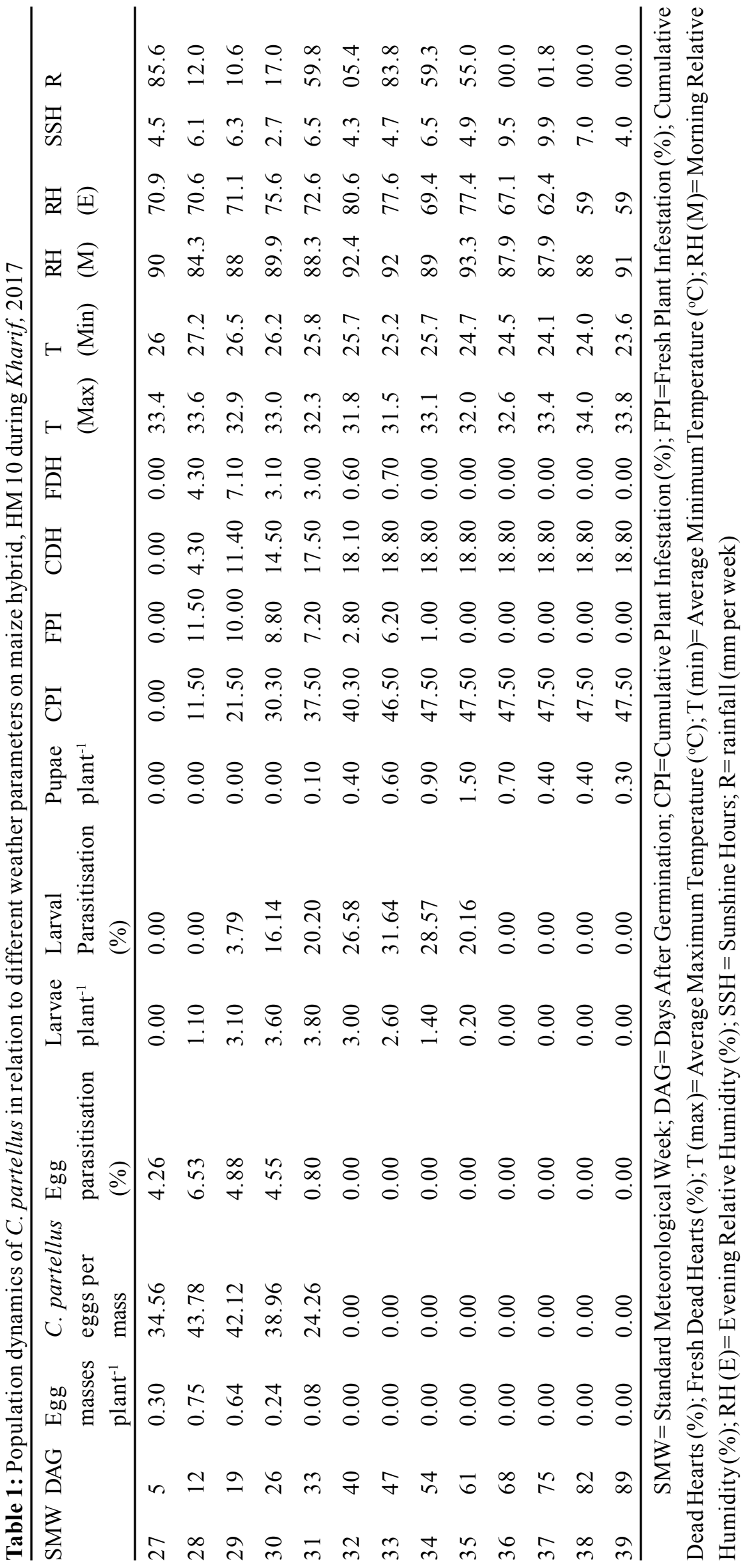


Similar level of plant infestation by C. partellus has been reported in different parts of India and the world (Farid et al., 2007; Naz et al., 2003; Patel et al., 2016; Segeren et al., 1995). Maximum plant infestation was recorded during $33^{\text {rd }}$ SMW in Gujarat, however, dead hearts were maximum $(62 \%)$ in the month of July (Biradar et al. 2011).

Fresh plant infestation and fresh dead hearts exhibited positive correlation with minimum temperature, however, cumulative plant infestation and cumulative dead hearts had a negative correlation with minimum temperature (Table 2). Mahadevan and Chelliah (1986) also suggested positive relation between minimum temperature and plant infestation. Likewise, negative correlation $(\mathrm{r}=-0.527)$ of $C$. partellus plant infestation with minimum temperature was reported by Patel et al. (2016). Both cumulative and fresh plant infestation had a non-significant correlation with all other weather parameters, like Jeengar et al. (2010). Pragati et al. (2014) and Dhaliwal et al. (2018) also found similar relations between plant infestation and dead hearts, and different weather parameters. However, literature is silent on relation of fresh plant infestation and fresh dead heart formation with weather parameters.

\section{Multiple linear regressions}

Weather parameters accounted for 86 per cent variability in egg density of $C$. partellus over the entire duration of crop $\left(\mathrm{R}^{2}=0.86\right)$ and 82 per cent of this was contributed by average minimum temperature and rainfall i.e. these two were the most important factors responsible for fluctuations in egg density of C. partellus (Table 4 and Fig $1 \mathrm{a}, 1 \mathrm{c})$. Evening relative humidity accounted for significant 40 per cent variability (Table 5 and Fig 1e) in larval population of $C$. partellus out of the total variation of 68 per cent $\left(\mathrm{R}^{2}=0.68\right)$ (Table 4). Similarly, all meteorological parameters accounted for 57 per cent variability in pupal population of C. partellus $\left(\mathrm{R}^{2}=0.57\right)$ but no single weather factor explained it significantly (Table 4).

On the other hand, average minimum temperature was the single most important factor governing cumulative plant infestation by contributing 55 per cent of the total variability (Table 5 and Fig 3a). Abiotic factors were responsible for significant 93 per cent variability $\left(\mathrm{R}^{2}=0.93\right)$ (Table 4) in fresh plant infestation (regression equation Y5) and minimum temperature accounted for 62 per cent variability (Table 5 and Fig $3 b$ ). Average minimum temperature was reported to be the most important factor responsible for 43 and 50 per cent variability in cumulative (Fig 3c) and 
Table 3: Correlation between C. partellus and its egg and larval parasitoids

\begin{tabular}{llll}
\hline Parasitoids & Egg masses/plant & Eggs per mass & Larvae/plant \\
\hline Egg parasitoid, Trichogramma sp. & $0.941^{* *}$ & $0.957^{* *}$ & - \\
Larval parasitoid, C.flavipes & - & - & $0.591^{*}$ \\
\hline
\end{tabular}

*: Significant at $\mathrm{P}=0.05 \%$; *: Significant at $\mathrm{P}=0.01 \%$

Table 4: Multiple linear regression of C. partellus with weather parameters

\begin{tabular}{lll}
\hline & Multiple linear regression equations & $\mathrm{R}^{2}$ \\
\hline Egg masses (Y1) & $\mathrm{Y} 1=-10.175-0.023 \mathrm{X} 1+0.341 \mathrm{X} 2+$ & 0.86 \\
& $0.045 \mathrm{X} 3-0.022 \mathrm{X} 4+0.008 \mathrm{X} 5-0.003 \mathrm{X} 6$ & \\
Larvae (Y2) & $\mathrm{Y} 2=88.228-2.732 \mathrm{X} 1+1.232 \mathrm{X} 2-0.095 \mathrm{X} 3-$ & 0.68 \\
& $0.240 \mathrm{X} 4-0.420 \mathrm{X} 5-0.008 \mathrm{X} 6$ & \\
Pupae (Y3) & $\mathrm{Y} 3=-17.809+0.293 \mathrm{X} 1-0.242 \mathrm{X} 2-0.101 \mathrm{X} 3+$ & 0.57 \\
& $0.070 \mathrm{X} 4+0.135 \mathrm{X} 5-0.002 \mathrm{X} 6$ & 0.74 \\
Cumulative Plant infestation(Y4) & $\mathrm{Y} 4=1023.06-12.722 \mathrm{X} 1-14.597 \mathrm{X} 2-2.285 \mathrm{X} 3+$ & \\
& $0.199 \mathrm{X} 4-0.972 \mathrm{X} 5-0.073 \mathrm{X} 6$ & 0.93 \\
Fresh plant infestation(Y5) & $\mathrm{Y} 5=288.830-6.388 \mathrm{X} 1+2.877 \mathrm{X} 2-1.208 \mathrm{X} 3-$ & \\
& $0.411 \mathrm{X} 4-1.531 \mathrm{X} 5-0.055 \mathrm{X} 6$ & 0.69 \\
Cumulative dead hearts (Y6) & $\mathrm{Y} 6=404.595-6.720 \mathrm{X} 1-4.195 \mathrm{X} 2-0.536 \mathrm{X} 3-$ & \\
& $0.141 \mathrm{X} 4-0.454 \mathrm{X} 5-0.046 \mathrm{X} 6$ & 0.88 \\
Fresh dead hearts (Y7) & $\mathrm{Y} 7=-16.407-3.279 \mathrm{X} 1+4.122 \mathrm{X} 2+$ & \\
& $0.674 \mathrm{X} 3-0.523 \mathrm{X} 4-0.057 \mathrm{X} 5-0.050 \mathrm{X} 6$ & \\
\hline
\end{tabular}

$\mathrm{X} 1$ : Average maximum temperature $\left({ }^{\circ} \mathrm{C}\right) ; \mathrm{X} 2$ : Average minimum temperature $\left({ }^{\circ} \mathrm{C}\right)$; X3: Morning relative humidity $(\%) ; \mathrm{X} 4$ :

Evening relative humidity (\%); X5: Sunshine hours; X6: Rainfall(mm/week)

Table 5: Step wise multiple linear regression showing the contribution of major weather parameters in variability of different stages and damage of C. partellus

\begin{tabular}{lll}
\hline & Step-wise multiple linear regression equations & $\mathrm{R}^{2}$ \\
\hline Egg masses (Y1) & $\mathrm{Y} 1=-4.590+0.187 \mathrm{X} 2$ & 0.60 \\
& $\mathrm{Y} 1=-5.392+0.224 \mathrm{X} 2-0.003 \mathrm{X} 6$ & 0.82 \\
Larvae (Y2) & $\mathrm{Y} 2=-8.550+0.142 \mathrm{X} 4$ & 0.40 \\
Cumulative Plant infestation (Y4) & $\mathrm{Y} 4=313.804-10.956 \mathrm{X} 2$ & 0.55 \\
Fresh plant infestation (Y5) & $\mathrm{Y} 5=-78.39+3.239 \mathrm{X} 2$ & 0.62 \\
Cumulative dead hearts (Y6) & $\mathrm{Y} 6=112-3.823 \mathrm{X} 2$ & 0.43 \\
Fresh dead hearts (Y7) & $\mathrm{Y} 7=-36.178+1.486 \mathrm{X} 2$ & 0.50 \\
\hline
\end{tabular}

$\mathrm{X} 2$ : Average minimum temperature $\left({ }^{\circ} \mathrm{C}\right) ; \mathrm{X} 4$ : Evening relative humidity $(\%)$

fresh dead hearts (Fig 3d) respectively (Table 4 and 5). Contrary to this, Dhaliwal et al. (2018) reported 33.48 per cent variation in dead heart formation due to maximum temperature and evening relative humidity.

\section{CONCLUSION}

Peak egg and larval population occurred during $28^{\text {th }}$ and $31^{\text {st }}$ SMW, respectively whereas maximum cumulative plant infestation (47.5\%) and dead hearts (18.8\%) were recorded during $34^{\text {th }}$ and $33^{\text {rd }} \mathrm{SMW}$, respectively suggesting control measures should be initiated during early stages of crop growth. Larval population exhibited significant positive correlation with minimum temperature and evening relative humidity $(\mathrm{r}=0.635)$ but cumulative plant infestation and 
cumulative dead heart formation had a highly significant negative correlation with minimum temperature. Trichogramma sp. and Cotesia flavipes exhibited highly significant positive correlation with egg and larval population of C. partellus, respectively suggesting a positive density dependent response. Further studies are required to ascertain potential of egg and larval parasitoids at different release rates and this thorough knowledge of population dynamics studies of $C$. partellus in relation to biotic and abiotic factors will strengthen the development of efficient pest management strategies in future.

\section{ACKNOWLEDGEMENTS}

We gratefully acknowledge the guidelines, support and facilities provided by Head, Department of Entomology, CCS Haryana Agricultural University, Hisar and Regional Director, CCSHAU Regional Research Station, Karnal. We are also thankful to meteorological observatory of Central Soil Salinity Research Institute (CSSRI), Karnal for providing the required meteorological data.

\section{REFERENCES}

Ahmad, S., Haider, M.U., Subhani, M.N., Sarwar, M., Naseem, M.K., Mannan,A., Malik,A. andAli, Q.(2017). Evaluating the efficacy of Trichogramma chilonis and effect of abiotic factors on percentage infestation of Chilo partellus (Swinhoe) (Pyralidae: Lepidoptera). Int. J. Bio. Pharm. Allied Sci., 6(12): 2537-2546.

Biradar, S.R., Kotikal, Y.K. and Balikai, R.A. (2011). Seasonal incidence of insect pests and their natural enemies on maize. Int. J. Plant Prot., 4(2):402-405.

Devi, N. and Raj, D. (1996). Extent of parasitisation of Chilo partellus (Swinhoe) on maize by Apanteles sp. in mid hill zoneofHimachal Pradesh(India). J. Entomol. Res., 20(2), 171-172.

Dhaliwal, A.K., Brar, D.S., Mahal, A.K. and Jindal, J. (2018). Influence of weather parameters on incidence of maize stem borer, Chilopartellus (Swinhoe) in summer maize in Punjab, India. J. Agrometeorol., 20(2):174-176.

Dharmasena, C.M.D. (2002). Temporal distribution of maize stem borer, Chilo partellus (Swinhoe) in relation to weather factors. Trop. Agric, 151, 1-6.

Divya, K., Marulasiddesha, K.N., Krupanidhi, K. andSankar, M. (2009). Population dynamics of spotted stem borer, Chilopartellus (Swinhoe) and its interaction with natural enemies in sorghum. Indian J. Sci. Tech., 3(1):70-74.
Fand, B.B., Tonnang, H.E.Z., Bal, S.K. and Dhawan, A.K. (2018). Shift in the manifestations of insect pests under predicted climatic change scenarios: Key challenges and adaptation strategies. In: "Advances in Crop Environment Interaction”. (Eds. S.K. Bal et al.).pp.389404, Springer Nature Singapore Pte Ltd.

Farid,A., Khan, M.I.N., Khan,A., Khattak, S.U.K. and Sattar, A. (2007). Studies on maize stem borer, Chilo partellus in Peshawar Valley. Pak. J. Zool., 39(2):127.

Harris, K. (1990). Bio-ecology of Chilo species. Int. J. Trop. Insect Sci., 11:467-a77. Indiastat. (2018). https:// www.indiastat.com/table/agriculture/2/maize

Jalali, S.K. and Singh, S.P. (2003). Determination of release rates of natural enemies for evolving biointensive management of Chilo partellus (Swinhoe)(Lepidoptera: Pyralidae). Shashpa., 10(2):151-154.

Jeengar, K.L., Srivastava,A.K. andAmeta, O.P.(2010). Influence of abiotic factors of the environment on major insect pests of maize. Indian J. App. Ent., 24(1):40-42.

Kandalkar, H.G., Men, U.B.,Atale, S.B. and Kadam, P.S. (2000). Effect of meteorological factors on incidence of sorghum stem borer, Chilo partellus (Swinhoe). J. App. Zool. Res., 13(1):69-70.

Khan, J., Ali, R., Blouch,A., Javed, H.I., Haq, E.U., Mehmood, T. and Rasool,A. (2017). Biological parameters of Cotesia flavipes reared on different larval instars of Chilo partellus under laboratory conditions. J. Entomol. \& Zool. Stud., 5(3):829-832.

Kumar, V. and Kanta, U. 2011. Effectiveness of Trichogramma chilonis Ishii in the suppression of Chilo partellus (Swinhoe) in summer maize. J. Bio. Cont., 34d:92-97.

Mahadevan, N.R. and Chelliah, S. (1986). Influence of intercropping legumes with sorghum on the infestation of the stem borer, Chilo partellus (Swinhoe) in Tamil Nadu, India. Int. J. Pest Manag., 32(2):162-163.

Mathur, L.M.L. (1991). Genetics of insect resistance in maize. Maize Genetics Perspectives, 238-259.

Mohan, B.R., Verma, A.N. and Singh, S.P. (1991). Periodic parasitisation of Chilo partellus (Swin.) larvae on forage sorghum in Haryana. J. Insect Sci., 4(2):167-169.

Naz, F., Hussain, M. and Din, M. (2003). Insect-pests of maize and their losses. Asian J. Plant Sci., 2(5):412-414.

Neupane, F.P., Coppel, H.C. and Chapman, R.K. (1985). 
Bionomics of the maize borer, Chilopartellus(Swinhoe) in Nepal. Int. J. Trop. Insect Sci., 6(4):547-553.

Ngoko, Z., Cardwell, K.F., Marasas, W.F.O., Wingfield, M.J., Ndemah, R. and Schulthess, F. (2002). Biological and physical constraints on maize production in the Humid Forest and Western Highlands ofCameroon. Eur. J. Pl. Path., 108:893-902.

Panwar, V.P.S. (2005). Management of maize stalk borer, Chilo partellus (Swinhoe) in maize. Stresses on Maize in the Tropics" (PH Zaidi, NN Singh, eds.). Directorate of Maize Research, New Delhi, 376-395.

Panwar, V.P.S., Mukherjee, B.K. andAhuja, V.P. (2000). Maize inbreds resistant to tissue borer, Chilo partellus and Atherigona spp. Indian J. Genet. Pl. Br., 60(1):71-75.

Patel, J.R., Varma, H.S. and Shinde, Y.A. (2016). Population dynamics of maize stem borer, Chilo partellus and its natural enemies. Indian J. Ent., 78(2):126-128.

Patel, P.J., Borad, P.K. and Parmar, K.D. (2005). Population fluctuation of stem borer, Chilo partellus (Swinhoe) infesting maize in relation to weather parameters. $G A U$ Res. J., 30(1-2): 60-63.

Pats, P., Ekbom, B. and Skovgård, H. (1997). Influence of intercropping on the abundance, distribution and parasitism of Chilo spp. (Lepidoptera: Pyralidae) eggs. Bul. Entomol. Res., 87(5): 507-513.

Pragati, M., Sreenivas, A.G., Prakash, K., Jat, M.L., Prabhuraj, A., Manjunath, N. and Singh, Y.K. (2014). Population dynamics of shoot fly and stem borers of maize under conservation agriculture system. J. Exp. Zool., 17(2):563-566.

Rao, G.M.V.P., Ramani, S. and Singh, S.P. (2001). Field parasitisation of the maize stem borer, Chilo partellus (Swinhoe) (Lepidoptera: Pyralidae) in Bangalore. $J$. Bio. Cont., 15(2):193-196.
Reddy, K.V.S. and Zehr, U.B. (2004). Novel strategies for overcoming pests and diseases in India. NewDirections for a Diverse Planet, Proceedings of 4th Intl. Crop Science, Brisbane, Australia., 26.

Segeren, P., van Den Oever, R. and Slobbe, W. (1995). Seasonal abundance, damage, cultural control methods and varietal resistance of the four main pest and disease problems in irrigated maize in southern Mozambique. Int. J. Trop. Insect Sci., 16(3-4):263-277.

Shrivastava, M.D. (2015). Augmentative Management of Chilo partellus (Swinhoe) by Cotesia flavipes Cameron in Maize crop (Doctoral dissertation, Rajendra Agricultural University, Pusa (Samastipur)).

Singh, G. and Jaglan, M.S. (2018). Seasonal incidence of different insect-pests in Kharifmaize. J. Pharmacogon. Phytochem., 7(3):3666-3669.

Singh, G., Jaglan, M.S. and Verma, T. (2018). Management of maize stem borer, Chilo partellus (Swinhoe) in Kharif maize with cowpea intercropping. J. Entomol. Zool. Stud., 6(3): 1791-1794.

Sylvain, N.M., Manyangarirwa, W., Tuarira, M. and Onesime, M.K. (2015). Effect of the Lepidoptera Stem Borers, Busseola fusca (Fuller) and Chilo partellus (Swinhoe) on Green Mealies Production. Int. J. Inn. Res. Dev., 2015; 4(10):366-374.

Trehan, K.N. and Butani, D.K. (1949). Notes on the life-history bionomics and control of Chilo zonellus (Swinhoe) in Bombay Province. Indian J. Ent., 11:47-59.

Vijay, K. and Uma, K. (2011). Effectiveness of Trichogramma chilonis Ishii in the suppression of Chilo partellus (Swinhoe) in summer maize.J. Bio. Cont., 25(2): 92-97. 